\title{
Preparation and Characterization of Unconventional Lanthanum Cerium CopurateThin Films Superconductors for Development of Thermoelectric Devices
}

\author{
Kaltham B.Aljaloud ${ }^{1}$, Anna Kusmartsevam ${ }^{2}$, Mervette El Batouti ${ }^{3^{*}}$ \\ ${ }^{I}$ Department of Physics, Qassim University,Saudi Arabic Kingdom \\ ${ }^{2}$ Department of Physics, school of science, Loughborough, United Kingdom \\ ${ }^{3}$ Chemistry Department, Faculty of Science, Alexandria University.
}

*Corresponding Author: Mervette El Batouti, Chemistry Department, Faculty of Science, Alexandria University.

\begin{abstract}
Temperature dependences of thermal conductivity ( $k$ )and electrical resistivity,for two prepared samples (s1, s2) of Lanthanum Cerium Copurate Thin:La2-xCex CuO4 (LCCO)with dopingCepercent $(x \approx 0.10)$, for $(s 1),(x \approx 0.12)$ for $s 2$ of electron-doped high temperature superconductors La2- $x C e x C u O 4$. Superconductors obtained asan ultra thinfilm witha thickness of less than 100 mmon SrTiO3 substrate.A promising modified steady-state method was used for measurement of thermal conductivity for one optimally doped s2 and one slightly overdopeds1 at the temperature range of 3-270K, inthe absence of any applied magnetic field.The errors due heat flow in led wires and heat loss by radiation were minimizedvia fixedthe heatingrate of one end andthe coolingrate of the other end of the test sample.Each prepared sample showed a unique thermal conductivity with a maximum at a specific critical (Tc) temperature and an exponential dependence on temperature inthe lowtemperatureregion.Thedistinct behavior for $s 1$ and 2 is attributed to different doping percent $(x)$, and $O 2(g)$ content which altered the scattering of phonon.The temperature behaviorof $k$ for $s 1$ is more consistent with those found inunderdoped samples. However, electrical resistivity data imply that $s 1$ is slightly overdoped. This may be explained through possible changes in O2(g)content andthe possibility that s1 may actually be an underdoped sample with an increased O2(g)content. A sharp peak developedin kwhen superconducting transition or critical temperature (TC) approached. WiedermanFranz law was not valid over studied temperature range, signifying the presence of strong phonon contributions to $\kappa$ value that equals the sum of both lattice and electronic conductivity.
\end{abstract}

Keywords: thin film, thermal conductivity, doping, superconductors, Superconductors, thermal conductivity, electronic conductivity, phonon.

\section{INTRODUCTION}

Unconventional and high temperature superconductors are fascinating materials in modern solid state physics and materials science and are widely used in manufacturing of wires, tapes, cables, electrical electordes, etc...... Moreover, these thermoelectric materials (TE) are widely used for manufacturing of transistors and microelectronics. ${ }^{1}$ Superconductivity was exhibited by Hgbelow $T_{c}$ of $4.2 \mathrm{~K}$; (La-Ba$\mathrm{CuO}$ ) ceramicsat $\sim 30 \mathrm{~K} ; \mathrm{Y}-\mathrm{Ba}-\mathrm{O}$ at $93 \mathrm{~K}$; Bi and Tlcuprates at $125 \mathrm{~K}$; Hg-based cupratesat $164 \mathrm{~K}^{2} \mathrm{~A}$ perfect superconductor elements: $\mathrm{Pb}, \mathrm{Ta}$, and Snhave zero electrical resistanceand perfect diamagnetismif cooled below $\mathrm{T}_{c}{ }^{3}$ Cuprates are the bases of many superconductors of different $T_{c:} \mathrm{Ba}-$ $\mathrm{Ca}-\mathrm{CuO}) ; T_{c} 120 \mathrm{~K}[3], \mathrm{Ln}_{2-\mathrm{x}} \mathrm{Ce}_{\mathrm{x}} \mathrm{CuO}_{4}(\mathrm{Ln}=\mathrm{La}, \mathrm{Nd}, \mathrm{Pr}, \mathrm{Sm}$, or Eu) where electron-doped highTcsuperconductors are less good-understood than their hole-doped counterparts. ${ }^{4}{ }^{5}$ Electron-doped films exhibit superconductivity extending to $x$ below $0.10,(\mathrm{Pr}, \mathrm{La})_{2-\mathrm{x}} \mathrm{Ce}_{\mathrm{x}} \mathrm{CuO}_{4+\delta}$ compounds where $\mathrm{Tc}$ is a function of Ce-doping concentration. ${ }^{6}$ However,their measured thermal conductivity was be in doubt due to the errors introduced during experiment measurements ${ }^{6}$

Many reported methods for measurement of $\mathrm{k}$ have challenges. Static DC absolute techniques; rapid semi-quantitativeand transient method; Photoacoustictechnique. ${ }^{7}$ Challenges in steady-state methods, isdue to the heat sink. ${ }^{8}$ However Wiedermann-Franz (WF) lawdetermine electronic thermal conductivityk $_{e}$; Comparative technique (standard in the series between the heater and sample; $3 \omega$ 
technique accurately measuresk andthe heat capacity of a material for a simple heater geometry using diffusion equation. ${ }^{9}$

Temperature measured by thermocouple depending on Seebeck effect that is a function of the temperature difference $(\Delta \mathrm{T})$ may give a reliable measurement of $\mathrm{k}$. Electrons diffuse from the hot end toward the cold end of a conductorand a potential difference developed that is directly proportional to $(\Delta \mathrm{T})$ between the heater $\left(\mathrm{T}_{\mathrm{H}}\right)$, and the sink $(\mathrm{Ts}) .^{10}$

Seebeck effect, $S=\frac{\Delta V}{\Delta T}=\frac{\Delta V}{\left(T_{H}-T_{S}\right)}$

$\Delta V=\left(V_{H}-V_{S}\right)=\int_{T_{0}}^{T} S d T=-S\left(T_{H}-T_{S}\right)=-S \Delta T$

Two different metals or alloy'send, $\Delta \mathrm{V}$ developmeasurethe temperature (T)at a local position, electric current flow due to $(\Delta \mathrm{T}) .{ }^{11}$ Joining equal-length strips of two metals attwo ends making a loop, where one end of two junctions was dipped in a source of boiling water and the other end in cold sink. Size of electric current flows through loop directly related to $\Delta \mathrm{T}$. At low temperature, type $\mathrm{E}$ thermocouplewas determined to measurethe temperature at two different locations on thin film, ${ }^{12}$. Calibration Tables areused to convert thermal electromotive force (e.m.f) of a thermocouple to temperature, via differential reference method.$^{13}$

\section{EXPERIMENTAL}

In this work, thermal conductivity measurements were conducted on a copper $(\mathrm{Cu})$ sampleand the preparedsamples of LCCO superconductorsusinga thermocouple probe of two metal alloys under optical microscopic investigation. The potential difference, $\Delta \mathrm{V}$ developedand electric current flow due to $\Delta$ Tbetweenthe two metal ends.A sensitive E- type thermocouplewire probes (chromel $(90 \% \mathrm{Ni}, 10 \%$ $\mathrm{Cu})+$ constantine $(55 \% \mathrm{Cu}, 45 \% \mathrm{Ni})$ was used to monitor voltage at low temperature.To optimizethe experimental condition, chromel, constantan wires of thermocouple probeswere of different diameters, Table (1), cut into equal parts, glued onto the test sample at a particular location using silver (Ag)-loaded epoxy adhesive and hardener. The two wires twisted together, glued by Ag epoxy to formthermocouple formingwire probes.The Evo-stick two-parts, rapid adhesive glue have good $\mathrm{k}$ to ensure that the thermocouple will be in thermal equilibrium with sample, and it is thermally stable through the measurement cycling. An insulated copper wirewas used as external wiring connections.

Table1. Wires materials with various diameters.

\begin{tabular}{|l|l|}
\hline Material & Diameter $(\mathbf{d})$ \\
\hline Chromel $(\mathrm{Ni} / \mathrm{Cr})$ & $0.025 \mathrm{~mm}$ \\
\hline Constantan $(\mathrm{Ni} / \mathrm{Cu})$ & $0.025 \mathrm{~mm}$ \\
\hline $\mathrm{Cu}$ (insulated) & $0.125 \mathrm{~mm}$ \\
\hline Thick $\mathrm{Cu}$ (insulated) & $\approx 1.0 \mathrm{~mm}$ \\
\hline
\end{tabular}

nsulatedthin $\mathrm{Cu}$ wires $(\mathrm{d} \approx 0.125 \mathrm{~mm})$ was connected directly to the sample. The thick $\mathrm{Cu}$ wires $(\mathrm{d} \approx 1.0 \mathrm{~mm})$ connected theelectrical inputs(nanovoltmeter, current source,lock-in amplifier). Two types of wires were used because samples are very small $(\approx 5 \mathrm{~mm})$. The insulation was removed from $\mathrm{Cu}$ wire ends, and the exposed end of $\mathrm{Cu}$-wires were coated with a thin layer of suitable solder:: $40 \%$ lead $(\mathrm{Pb})$ plus $60 \%$ tin $(\mathrm{Sn})$ at soldering temperature $\approx 300 \mathrm{oC}$. This tinning protectedCu from air oxidation and improved soldering contact. The thermal conductivity of acopper sample was tested by taking high thermally conductive $\mathrm{Cu}$ foil, $\mathrm{kCu}=400 \mathrm{~W} /(\mathrm{K} . \mathrm{m})$ used to check the validity of experimental method.14Test, measurement set up, is shown in Table 2.

Table2. Dimensions of copper foil reference test sample.

\begin{tabular}{|l|l|l|l|}
\hline Dimensions & $\mathrm{Cu}$ & Error & \%error \\
\hline Length l (mm) & 3.0 & 0.1 & 3 \\
\hline Width $\mathrm{w}(\mathrm{mm})$ & 3.0 & 0.1 & 3 \\
\hline Thickness d $(\mathrm{mm})$ & 0.30 & 0.05 & 16 \\
\hline
\end{tabular}

Modification of the steady state method for measuring $\mathrm{k}$ was carried as follows: a Vera board havingof vertical $\mathrm{Cu}$ conducting tracks, isused (Figure 1). The sample was connected on one end of the board and a thick external $\mathrm{Cu}$ wire was connected tothe otherend and wassoldered to BNC connectors, 
number 3 wasattached tothe electrical inputs of devices (nanovoltmeter, current source,...). One sample end was glued to the "cold sink" (a simple brass post (Figure 1-number 4)usingquickly driedand mechanically strong GE varnish glue. A heater (a chip resistor of $\mathrm{R}=100 \mathrm{ohm}$ (with knowingpower, $\mathrm{P}$ = RI2) wasattached to the other sample end(Figure1-number 2). The $\Delta \mathrm{T}$ between the heater and the cold sinkwas established across $\mathrm{Cu}$ foil as a test sample and measuredThot, and Tcold using the thermocouple junctions attached at two positions.

$$
\mathrm{k}_{\mathrm{Cu}}=\mathrm{P} \times \frac{1}{[(\mathrm{w} \times \mathrm{d}) \Delta \mathrm{T}]}=\frac{1}{\left[(\mathrm{w} \times \mathrm{d})\left(\mathrm{T}_{\text {hot }}-\mathrm{T}_{\text {cold }}\right]\right.}=(1 / 378) \times(3 /(3 \times 0.3)) \times 10^{3}=8.8(\mathrm{~W} / \mathrm{Km})
$$

The obtainedvalues ofkCuwerecompared to the known value: $\mathrm{kCu}=400 \mathrm{~W} /(\mathrm{K} . \mathrm{m})$. It is likely that only a part of the heater power was transmitted through the sample and only $2.2 \%$ of heaterpower was going into $\mathrm{Cu}$ foil.During measurement of $\mathrm{k}$ of the prepared LCCO thin film samples, the errors sources attributed aerated conditions air and the heat transfer by convection contributionto the heat flow and thepurity of the testedCu foil is high to avoid biasing of the results were minimized.

Connections of Vera board and wireswere made through solder joints (Figure1- number 3) at 300oC. All connection pointswere tested for electrical continuity using a voltmeter. Thermal conductivityof LCCO films carried out usingathermocouples of the twometalalloys chromel and Constantine glued at two specific locations on the sample. Measuring Thot,Tcoldof the heater connected at one sample endand the heat sink connected atthe opposite end, The geometric dimensions(width, w) of the substrate plus the film were recorded. The film thickness $t$, the distance between the two thermocouple junctions wereobtained.

In this study, alinear $\Delta$ Tis assumed which is a valid approximation for small distances $(\approx 10 \mathrm{~mm})$ to include the physical effects of the heater connections, interfaces and the power loss due to the cables or the connections isminimized.15-22

In our study, It is thought that the error source of estimation of sample's geometry and thequality of $\mathrm{Cu}$ foil surface is controlled, Table(2). However, the total error due to the geometric factor $\approx 5 \%$ did between themeasured $(\mathrm{kCu})$ and the accepted value of $\mathrm{kCu}=400$ (W/K.m) for $\mathrm{Cu}$. Theerror sourceof $\mathrm{Cu}$ foil surfacequality is minimized and controlled by working the expermimental measurements under deareated conditions.

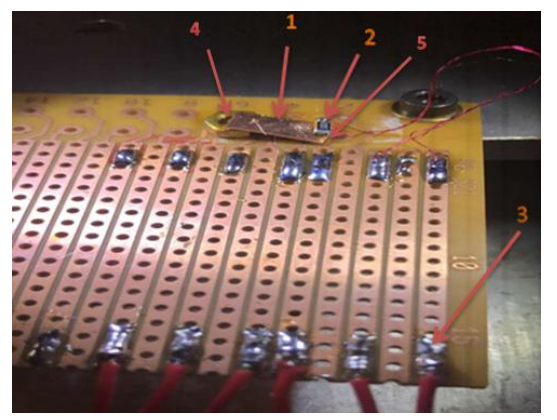

Figure1.Soldering station with a circuit board.

Where:1 thermocouples; 2 heater; 3 solder points.; 4 cold sink; 5-Cu foil.

\section{RESULTS AND DISCUSSION}

The voltage developed across the thermocouple was monitored with time, and represented in Figure 2 where: $\Delta \mathrm{V}=$ Vhot-Vcold wasdetermined.

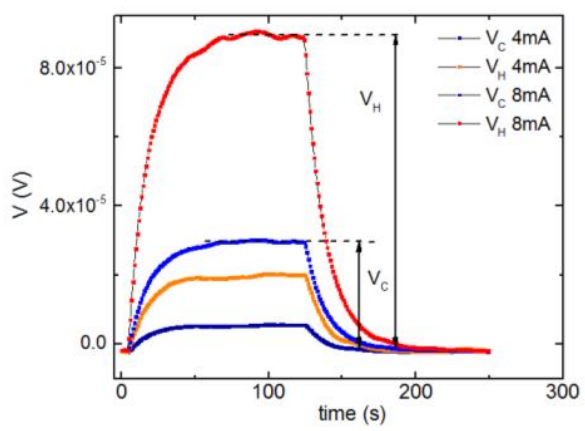

Figure2. Two heater current values induce different voltages $V H$ and $V C$. 
A current pulse applied tothe small sample heater and current response with time on thermocouple measured. Thermocouple voltage in an $\mathrm{ON}$ and OFF state of heater measured. A comparison between steady-state (time-independent voltage, DC) between ON and OFF heater state, determine thermocouple voltage: $\mathrm{V}=\mathrm{VON}-\mathrm{VOFF}$ )atdifferent currents density: 4mA, and $8 \mathrm{~mA}$. The thermal voltage related to $\mathrm{TH}$ and TCAt $8 \mathrm{~mA}$, higher heater power ( $\mathrm{P}=\mathrm{I} 2 \mathrm{R}$ and large thermal voltages (red and blue points, Figure 3). Measured voltages for $\mathrm{I}=4 \mathrm{~mA}$ is much lower..To generatedvoltagein thermocouple reflecting the potential difference both cold VC, hot VH. In Figure 3, $\Delta \mathrm{T}$ plotted against thermopower $(\mathrm{P})$ showing the direct proportionality between the electrical power $(\mathrm{P})$, and $\Delta \mathrm{T}$ in accordance with Seebek effect.

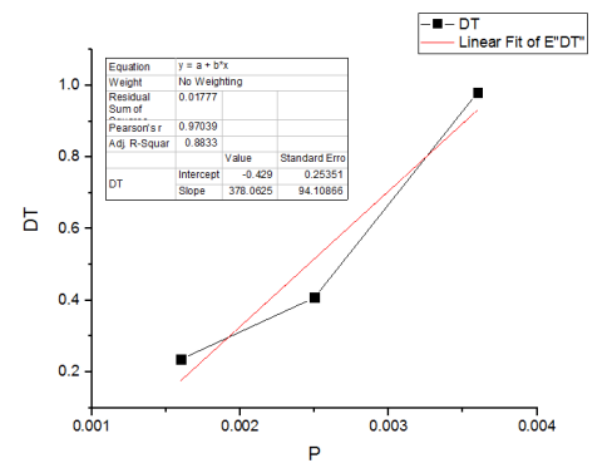

Figure3.Difference $\Delta T$ against thermopower $P$.

The temperature increased linearly with increasing thermopower $(\mathrm{P})$. The red line represents a fitting of curve using a linear equation:

$\Delta \mathrm{T}=\mathrm{a} * \mathrm{P}+\mathrm{b}$

The fit is moderately good with $\mathrm{R} 2=0.8833$. Coefficient $\mathrm{a}=378(\mathrm{~K} / \mathrm{W})$, and these parameters were used to calculate k.The validity of equation (4) in our study of LCCO thin film indicated that the modified thermal setupused for measuringk of the samples in this study is valid and acceptable.Figure 4 clarified that that as the electric power $(\mathrm{P})$ of the heater increased, as the temperature difference (Thot-Tcold)was increased.

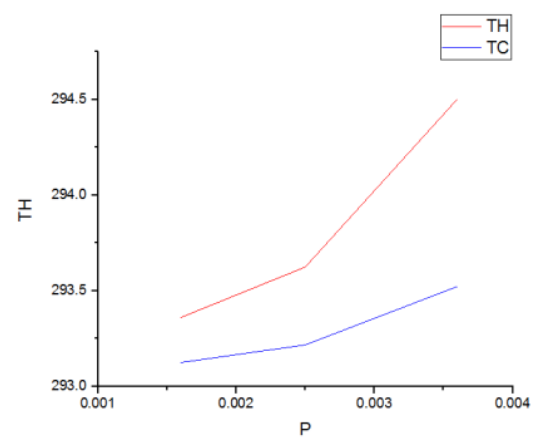

Figure4. Temperature of thermocouple TH, and TCagainst heater power $P$.

Figure4, showed two curves representing the temperature of thermocouple hot:Thot, $\mathrm{T}$ cold plotted against power $(\mathrm{P})$. A significantly higher $(\mathrm{TH}, \Delta \mathrm{T}=$ Thot-Tcold) was observed.

\subsection{Preparation of $L$-platform and electrical connections for measurement of $k$ for $L C C O$.}

The two prepared (LCCO)thin films with different Ce-doping (x)were described in Table3 corresponding to: $5 \mathrm{~K}<\mathrm{TC}<27 \mathrm{~K}$ measured through the thermal transport.

Table3. Sample description.

\begin{tabular}{|c|c|}
\hline Samples & Chemical formula \\
\hline $\mathrm{S}_{1}$ & $\mathrm{La}_{2-\mathrm{x}} \mathrm{Ce}_{\mathrm{x}} \mathrm{CuO}_{4}(\mathrm{x} \approx 0.12)$ \\
\hline $\mathrm{S}_{2}$ & $\mathrm{La}_{2-\mathrm{x}} \mathrm{Ce}_{\mathrm{x}} \mathrm{CuO}_{4}(\mathrm{x} \approx 0.10)$ \\
\hline
\end{tabular}

Sample thin geometry is shownin Table 4 indicated that both thesamples areair stable and stored outside a desiccator. 
Preparation and Characterization of Unconventional Lanthanum Cerium CopurateThin Films Superconductors for Development of Thermoelectric Devices

Table4. Samples s1 and s2 geometry dimensions:

\begin{tabular}{|c|c|c|}
\hline LCCO & S1 & S2 \\
\hline Width & $3 \mathrm{~mm}$ & $3 \mathrm{~mm}$ \\
\hline Length & $1.8 \mathrm{~mm}$ & $2.4 \mathrm{~mm}$ \\
\hline Thickness & $200 \mathrm{~nm}$ & $200 \mathrm{~nm}$ \\
\hline Error & 0.1 & 0.1 \\
\hline
\end{tabular}

\subsection{Making electrical connections to L-shaped Platform}

The experimentwas started with a blank L-platform. Plastic tracks attached to Ni pads to the L shaped platform. Pads soldered to and used as connection points for the wiresfrom the sample and cryostat connector. Plastic tracks attached to L-platform using a STYCAST resin- STYCAST 2850 FT. Resin STYCAST 2850 FT and CATALYST 23 LV are mixed in right proportions $7.5 \%$ weight using.Small amounts of powder $\mathrm{Al}_{2} \mathrm{O}_{3}$ catalyst was added to STYCAST 2850FT until a viscous mixture to improve thermal conductivity andmechanical strength of TYCAST. Once mixed, resin was used to attach plastic tracks - in two rectangular, thin strips to L-platform - at either edge (Figure 5number 1).Thin insulated $\mathrm{Cu}$ wires $(\mathrm{d}=0.125 \mathrm{~mm})$ was cut in equal sized segments of $7-8 \mathrm{~cm}$, endstinned, twisted into pairs to improve soldering contacts and reduce induction noise. One end of a twisted wire pair soldered onto Ni-pads on the L - platform, and other end soldered to a 12-pin connector from which8 connections used. Pins 1 and 2 were for hot thermocouple $\mathrm{T}_{\mathrm{H}}^{+}$and $\mathrm{T}_{\mathrm{H}}^{-}$ respectively. Pins 5,6$)$ were for cold thermocouple $\mathrm{T}^{+}{ }_{\mathrm{C}}$ and $\mathrm{T}_{\mathrm{C}}^{-}$respectively. Pins 11 and 12 deliver the current through the heater, pins 9 and 10 were used to perform a four points measurement ofheater resistance Ras shown in Figure (5).

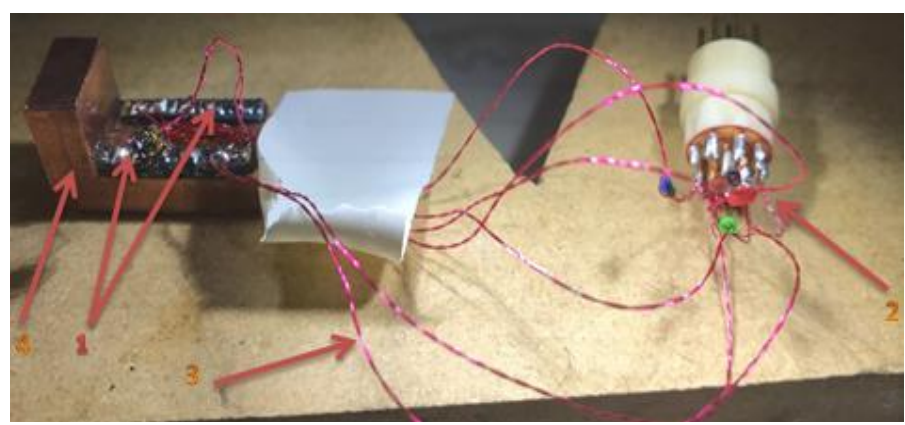

Figure5. L-platform with electrical connections. 1 STYCAST resin connecting tracks; 2 - 12-pin connector attaching to cryostat; 3-Cu wire; 4 L-platform.

Sample attached with L-shaped platform using a STYCAST resin - STYCAST 1266 (part A), part B (ethyleneoxy) bis (propylamine) were mixed in right proportions $28 \mathrm{wt} \%$ of part, and small amounts $\mathrm{Al}_{2} \mathrm{O}_{3}$ powder was addedto STYCAST until a viscous mixture obtained,Mixturewas putin (Hotbox Oven With Fan at $70^{\circ} \mathrm{C}$ for $5 \mathrm{~min}$. to be viscous and to minimize out gassing in desiccator. A suitable mixture obtained and was attachedto the sample in the platformby glue (Figure 6).

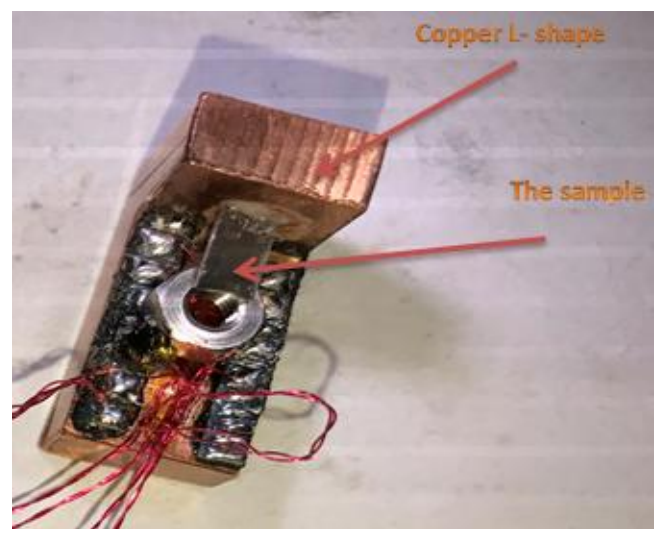

Figure6. Sample attached withL-shaped platform.

Sample attached to theheater tousingSTYCAST 1266resin prepared by the same process of the last stage. The samplewas put in a desiccator, because LCCO is air sensitive. (Figure 7) 


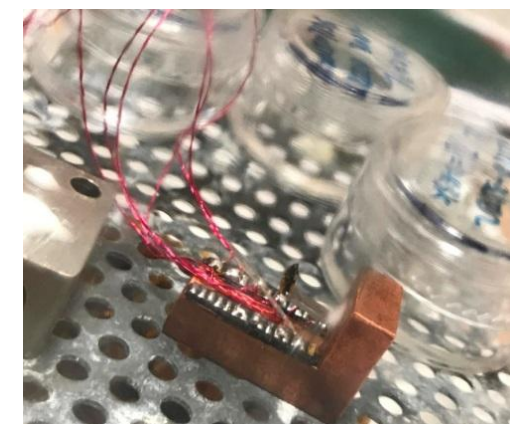

Figure7. Sample attached with small heater.

So, two thermocouples used during k measurement, (Figure 8).

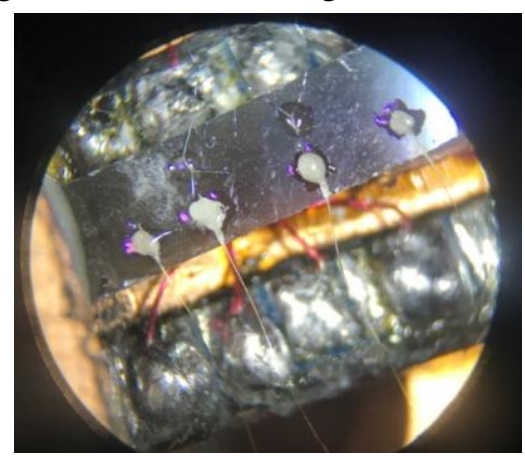

Figure8. Thermocouples under microscopic.

\subsection{Cryogenic experiments}

LowCryogenic temperatures $3-295 \mathrm{~K}$ used to study LCCO achieved using a Gifford McMahon closed cycle cryostat under an ultra-high vacuum of $\sim 10^{-5}$ mbar using a combination of a roughing and a turbo pumps to minimize heat convection through the surrounding medium .18, 19-22Low temperatures 3Kobtained using a Gifford McMahon closed cycle cryostat system consists of 2 stages, measurements conducted on 2nd stage [16].The sampleis attached electrical connectors Au leads to sample and gluing L-shaped platform to cryostat platform,Figures 9and 10 showed the connection of the sample with cryostat.

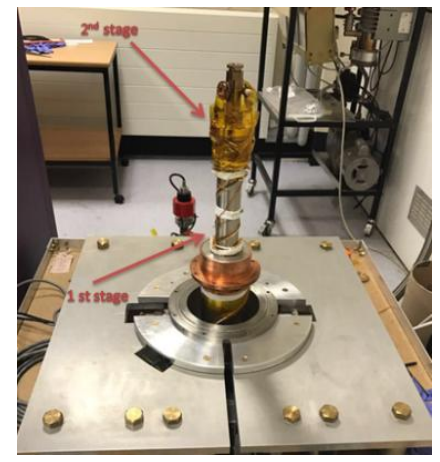

Figure9. Different stages in the cryostat system.

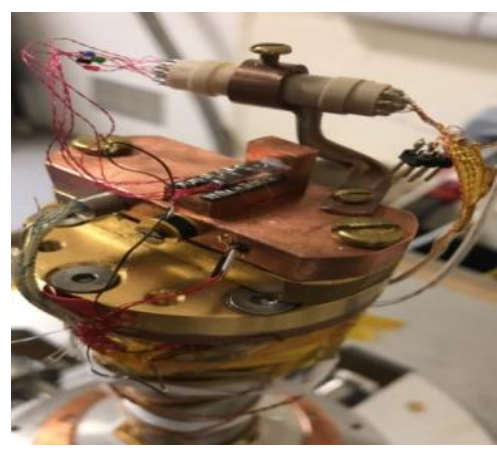

Fig10. Sample with cryostat. 
Preparation and Characterization of Unconventional Lanthanum Cerium CopurateThin Films Superconductors for Development of Thermoelectric Devices

Table5. showed the complete description of the cooling conditions. Temperature and cooling power for cold sink component.

\begin{tabular}{|c|c|c|}
\hline Cold head component & Temperature $(\mathrm{K})$ & Cooling Power $(\mathrm{W})$ \\
\hline $1^{\text {st }}$ stage & $40 \mathrm{~K}$ & $\sim 50 \mathrm{~W}$ at $40 \mathrm{~K}$ \\
\hline $2^{\text {nd }}$ stage & $3 \mathrm{~K}$ & $\sim 1.0 \mathrm{~W}$ at $4 \mathrm{~K}$ \\
\hline Exterior of cryostat & $295 \mathrm{~K}$ & 0 \\
\hline
\end{tabular}

Gifford-McMahon (GM) refrigerator in cryostation systemduring a cyclewas used. Fig11 showed a simplified description of this technicality [23].A temperature versus entropy diagram of cycle. Fig 11illustratedthecooling cycle process of the system components. (from top left-right, bottom left-right) [25].

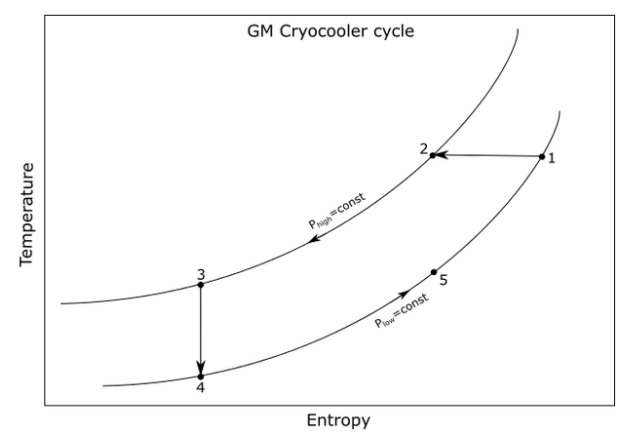

Figure11.Temperature versus Entropy diagram in Gifford-McMahon cooling cycle[25].

By motor displacer driven, at any period during the cycle when displace either at the chamberbottom or to because of forced motor.Rotating valve sometimes used in description of GM cooler replaced by a high pressure and low pressure, And closure of a valve, or closure of a given port can indicate by cross on port. As a separate chamberregenerator in parallel withchamber holding Displacer(because regenerator embedded within displacer). Sample area can be thought of as a heat exchanger in thermal contact directly with lower chamber under the displacer.

Figure (11) showed that at point 1-2: at bottom with displacer,constant temperature, high pressure inlet opened and upper chamber pressurized; at points 2-3 and low pressure exhaust port was closed, displacermoved to topforcing move gas out from the top chamber out of regenerator to the lower chamber at constant pressure for gascooling due to operations 4-5-1 which already cooled regenerator.At points 3-4: atthe top with displacer, low pressure exhaust port opened to allow gas in the lower chamber to cool and expand. Expansion for displaced some gas out during exhaust port for doing some work. In GM cycle for cooling gas, direct thermal contact drive heat out of sample spacepoints 4- 5-1: cooled stage, Displacer moving down with low temperature gas forced out of the chamber. Cooling regenerator, at low pressure port, gas leaves at a nearly ambient temperature .24-26

Thermal conductivity of two (LCCO) filmsdependence ontemperature in range 3-270Kis represented. The raw data obtained during warmup, starting from $3 \mathrm{~K}$. GM closed cycle refrigeration (CCR) crystalwas used. A Lab. view program automated measurement were carried out. Temperature sweeping rate and step improved themeasurementsaccuracy. At low temperatures, temperature step $0.2 \mathrm{Kwas}$ usedto investigate the transition between superconducting and normal states. At high temperatures, $1.0 \mathrm{~K}$ temperature step was used17.The data were analyzed through a custom written Python script. Measurement parametersof s1 and s2 were summarizedin Table 6.

Table6. Measurement parameters.

\begin{tabular}{|l|l|l|}
\hline Temperature range $\mathbf{( K )}$ & Temperature step $(\mathbf{K})$ & Sweep rate $(\mathbf{K} / \mathbf{m i n})$ \\
\hline $3-60$ & 0.2 & 0.2 \\
\hline$\sim 60-160$ & 0.5 & 0.3 \\
\hline$\sim 160-270$ & 1.0 & 0.5 \\
\hline
\end{tabular}

The electrical transport in Ce-doped (LCCO) samples was determined and the resistivity measurements yield TC-S1 $=23.5 \mathrm{~K}, \mathrm{TC}-\mathrm{S} 2=26.5 \mathrm{~K}$ for s 1 and $\mathrm{s} 2$ respectively. Transition estimated at $50 \%$ value of normal state resistivity. Doping percent of $\mathrm{Ce}$ estimated by comparingthe experimental Tc to the literature.26It was found that $\mathrm{s} 1$ is optimally doped sample withx $=0.1$ ands 2 isa slightly overdoped sample with $\mathrm{x}=0.12$. 
Thermal conductivity of $\mathrm{s} 1$ and s2showed in Figure (12)isin in good agreement with the published results.26A peakappearedinthe low temperature region. While $\mathrm{k}$ isalmost temperature independent at high temperatures, particularly for s1.Temperature behavior in $\mathrm{k}$ for $\mathrm{s} 1$ is more consistent with those found in underdoped samples [26],Figure(12). However, resistivity data imply that s1 is slightly overdoped. This may be explained through possible changes in $\mathrm{O} 2(\mathrm{~g})$ content as increasing $\mathrm{O} 2(\mathrm{~g})$ content increased the low temperature peak in k.26 Figure (12), It is possible that s1 may actually underdoped sample with increased $\mathrm{O} 2(\mathrm{~g})$ content $\mathrm{La} 2-\mathrm{xCexCuO} 4+$.The(LCCO)films s1and s2have TC-S1 $=23.5 \mathrm{~K}$ and TC-S2=26.5K. Figures 12,13 representedthe measurement of kdependent temperature for sample s1 and s2. The nominal composition from resistivitymeasurement is close to optimal approximately, $\mathrm{x}=0.12, \mathrm{x}=0.10$ for $\mathrm{s} 1$, and $\mathrm{s} 2$ respectively. Thepeak of $\mathrm{s} 1$ is much bigger than that of S2. Thermal conductivityof sample 1 is almost temperature dependent above $200 \mathrm{~K}$. However, the behavior of S2is quite different.

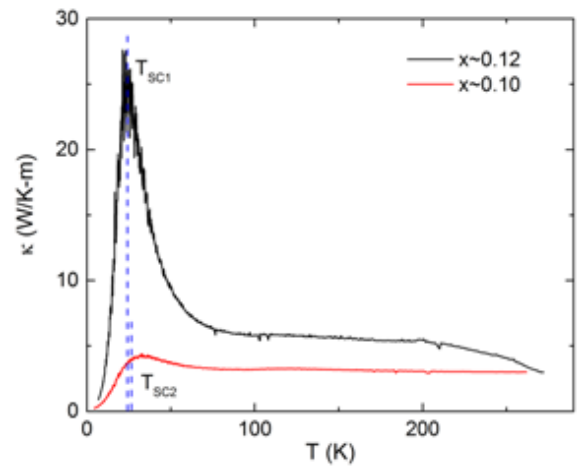

Fig12. Thermal conductivity $S 1$ and $S 2$ as a function of temperature of.

TSC1 and TSC2referred to the superconducting temperatures obtained from electrical transport. A sharp peak in $\mathrm{k}$ indicatesan approach to the superconducting state, may be important for its mechanism and origin.

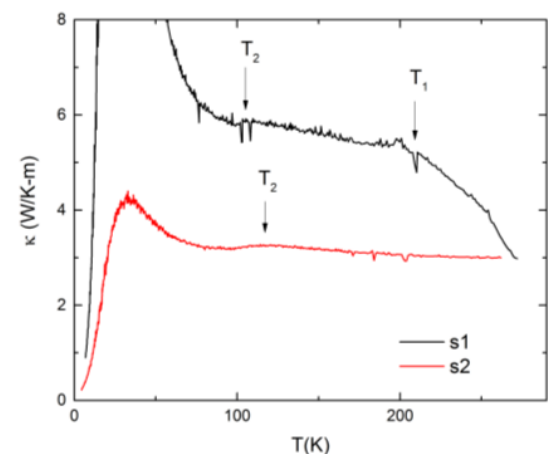

Figure13. Thermal conductivity measurement of $S 1$ and $S 2$ as a function of temperature.

$\mathrm{T}_{1}$ marks a significant change in temperature behavior of $\mathrm{k}$ for $\mathrm{s} 1$ then the behavior become almost temperature independent. Above T1, k rapidly decreases. T2 indicates the position of a slight peak inthermal conductivity (k) for s1 and s2 around 100K.

From resistivity andthe high-temperature thermopower results, s1 looks to be slightly overdoped, Cedoping $\mathrm{x} \approx 0.12$. However, $(\mathrm{k})$ values results not agree with this simple picture. For $\mathrm{s} 1$ thermal conductivity is significantly higher at lower temperatures than for $\mathrm{s} 2$. Peak around T TC is much more pronounced in $\mathrm{s} 1$ compared to $\mathrm{s} 2$ (Figure 13). At $\mathrm{T}>150 \mathrm{~K}$, $\mathrm{k}$ in $\mathrm{s} 1$ has a sharp change in slope marked at T1 (Figure 6.2). These features are all consistent with $\mathrm{k}$ temperature dependence found in underdoped samples (Figure 14). ${ }^{26}$ Suchunderdoped samples did not show superconductivity. Around $100 \mathrm{~K}$ a broad shoulder-like anomaly indicated at T2 becomes obvious both for s1 and s2 (Figure 12). This anomaly does not show strong doping dependence in the Ce-doping rangestudied.

It was reported that, doping dependence (k) of $\operatorname{Pr}_{1.3 \mathrm{x}} \mathrm{La}_{0.7} \mathrm{Ce}_{\mathrm{x}} \mathrm{CuO}_{4}$ looked to bein a good agreement to $\mathrm{s} 1 .{ }^{26}$ As Ce-doping increased both in-plane $\mathrm{k}_{\mathrm{ab}}$ and out-of-plane $\mathrm{k}_{\mathrm{c}}$ thermal conductivities decreasedandthe peak around $\mathrm{T}_{\mathrm{C}}$ becomes less pronounced. This finding may be attributed to the oxygen content in $\mathrm{s} 1$ that explained the observed discrepancy in comparison, influence of $\mathrm{O}_{2} \operatorname{onPr}_{1.3-}$ 
${ }_{x} \mathrm{La}_{0.7} \mathrm{Ce}_{\mathrm{x}} \mathrm{CuO}_{4}{ }^{26}{ }^{26}$ The out-of-plane $\mathrm{k}_{\mathrm{c}}$, low temperature peak isless pronounced when more $\mathrm{O}_{2}$ added.In-plane $\mathrm{k}$, no such significant changes observed. For s1, oxygencontent different from s2. If composition for $\mathrm{s} 1: \mathrm{La}_{2-\mathrm{x}} \mathrm{Ce}_{\mathrm{x}} \mathrm{CuO}_{4+}$ explain lower nominal doping $\mathrm{x}$, and high superconducting $\mathrm{T}_{\mathrm{C}}=23.4 \mathrm{~K}$.

The low temperature behavior of $\mathrm{k}$ was studied using the thermal exponential model:

$k=A T^{n}$

The data of thermal conductivityof s1 and s2 werefitted to determine the best value of the exponent (n).The obtained results are illustratedin Figure(14).

(a)

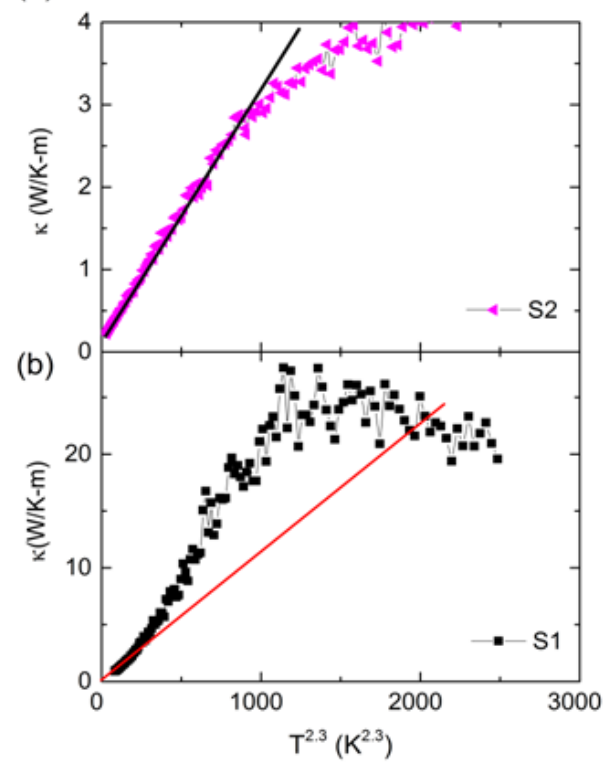

Figure14. Low temperature dependence of $k$ : (a) optimally doped LCCO s2 ( $x=0.10$, (b) slightly overdoped $\operatorname{sl}(x=0.12)$.

Figure 15 showed that thermal conductivity at low temperature (k) for s2 (optimal doping) showed a $\operatorname{good} \approx \mathrm{T}^{2.3}$ temperature dependenceand thermal exponents was valid up to $14-16 \mathrm{~K}$. While the values $\mathrm{k}$ for $\mathrm{s} 1$ (nominally slightly overdoped)did not follow this $\mathrm{T}^{2.3}$ behavior. This confirms that thedopingpercent, significantly affects the thermal transport of s1,and s2.

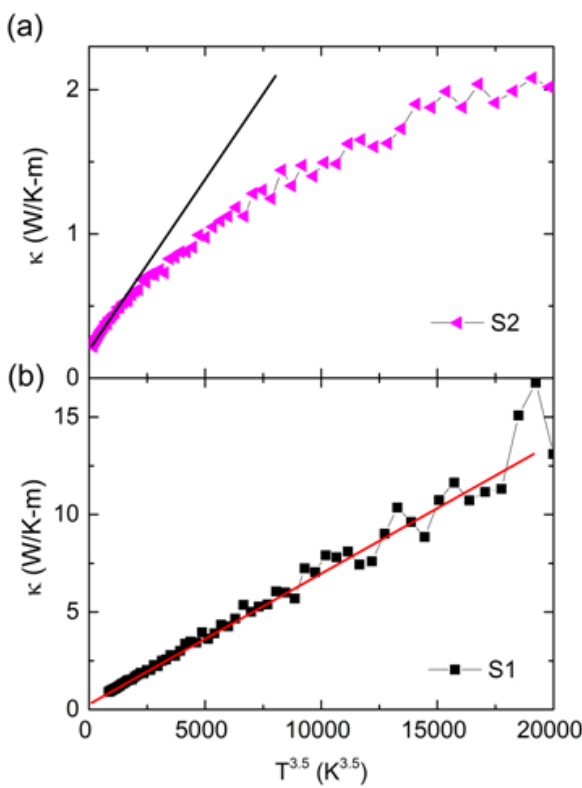

Figure15. An alternative model for temperature dependence of $k$ : (a) optimally doped $s 2(x=0.10)(b)$ slightly overdopeds 1 with doping $x=0.12$.

$\mathrm{k}$ for $\mathrm{s} 1$ shows a good $\sim \mathrm{T}^{3.5}$ temperature dependence. Whilek for $\mathrm{s} 2$ not follow the $\mathrm{T}^{3.5}$ behavior. 
The different behavior of $\mathrm{k}$ between $\mathrm{s} 1$ and $\mathrm{s} 2$ is substantial. It may be that a simple change in Cedoping not causethis difference in behavior. This low-temperature analysis adds further confirmation that $\mathrm{O}_{2(\mathrm{~g})}$ content should be considered.The electronic $\mathrm{k}$ calculated according to Wiederman-Franz law:

$\kappa_{e}=\frac{L_{0} T}{\rho}$

Where $\mathrm{L}_{0}=2.44 \times 10^{-8}{\mathrm{~W} \Omega \mathrm{K}^{-2}}^{2}$. Calculated electronic resistivity, $\kappa_{\mathrm{e}}$ for $\mathrm{s} 1$ at $270 \mathrm{~K}$

$\rho_{\mathrm{s} 1}(270 \mathrm{~K})=1.736 \times 10^{-5} \Omega-\mathrm{m}$.

$\mathrm{k}_{\mathrm{e}}(270 \mathrm{~K})=\mathrm{L}_{0} \times 270 / \rho=2.44 \times 10^{-8} \times 270 / 1.736 \times 10^{-5}=0.379 \mathrm{~W} / \mathrm{K}-\mathrm{m}$,

Total $\mathrm{k}_{\mathrm{s} 1}$ at $270 \mathrm{~K}: \kappa \sim 3.0 W K^{-1} \mathrm{~m}^{-1}$

Electronic thermal conductivity, $\kappa_{\mathrm{e}}$ is much less than total $\mathrm{k}, \kappa_{e} \ll \kappa$.

A similar trend was observed in $\mathrm{s} 2$ resistivity is $\rho_{\mathrm{s} 1}(270 \mathrm{~K})=2.05661 \times 10^{-5} \Omega-\mathrm{m}$. Same calculation was provided for $\kappa_{e s 2}$ :

$\mathrm{k}_{\mathrm{e}}(270 \mathrm{~K})=\mathrm{L}_{0} \times 270 / \rho=2.44 \times 10^{-8} \times 270 / 2.05661 \times 10^{-5}=0.320 \mathrm{~W} / \mathrm{K}-\mathrm{m}$

Total $\mathrm{k}_{\mathrm{s} 2}$ at $270 \mathrm{~K} \kappa \sim 3.0 W K^{-1} \mathrm{~m}^{-1}$

For optimally doped $\mathrm{s}_{2}$, much less than total $\kappa_{e}$ s2 $\ll \kappa$ implying that lattice and phonons contribute the thermal transport in thin film samples LCCO. Similar behavior found in other prviousely prepared cuprates superconductors. ${ }^{25}$ Table 7 showed the application Wiedermann-Franz ratio

Table7. $k$ of S1, S2 using Wiedermann-Franz ratio.

\begin{tabular}{|l|l|l|l|l|}
\hline Sample & keW/K-m) & $\begin{array}{l}\text { Electrical } \\
\text { resistivity, } \mathbf{\Omega}-\mathbf{m})\end{array}$ & Wiedermann-Franz ratio at 270K & $\mathbf{T}_{\mathbf{C}}(\mathbf{K})$ \\
\hline S1 & 0.379 & $1.736 \times 10^{-5}$ & 7.9 & 23.5 \\
\hline S2 & 0.320 & $2.05661 \times 10^{-5}$ & 9.4 & 26.5 \\
\hline
\end{tabular}

High Wiedermann Franz ratio $\gg 1$ indicatedstrong phononic processes inLCCO at optimally doping (s2) and slightly over doped (s1). A similar behavior in the temperature dependence of $\mathrm{k}$ in single crystal $\mathrm{La}_{1.602 x} \mathrm{Nd}_{0.40} \mathrm{Sr}_{x} \mathrm{CuO}_{4}(\mathrm{x}=50.12,0.15,0.20$ (a) in a-b plane, along c-axis. Lower part of (a) shows electronic contribution $\mathrm{k}_{\mathrm{e}}$ in the ab-plane from electrical data viaWiedemann-Franz law [15] where hole-doped cuprate superconductors: $\mathrm{La}_{1.602 x} \mathrm{Nd}_{0.40} \mathrm{Sr}_{x} \mathrm{CuO}_{4}$ in over-doped range. The values ofk calculated from Wiedermann Franz Law. The large discrepancy between me and total demonstrate that W-F law may not be valid over the entire temperature regime. However, W-F regime being approached with higher doping.

\section{CONCLUSION}

Thermal conductivity (k) studied for one optimally doped (s2) and one slightly overdoped (s1) sample (LCCO) films in the temperature range 3-270K. A sharp peak was developedin thermal conductivityas superconducting transition temperature TCis approached. Wiederman-Franz law was not valid over thestudied temperature range, signifying the presence of strong phonon contributions to the thermal conductivity. A peak in thermal conductivity is obtained at the low temperature region and there is an exponential decrease of $\mathrm{k}$ at the high temperature region. Wiederman-Franz law was not valid over the studied temperature range, signifying the presence of strong phonon contributions to the thermal conductivity. The values of keare much less than total thermal conductivity $\kappa_{-} \mathrm{e} \ll<\kappa i n d i c a t i n g$ that the lattice and phononsare the controlling

\section{REFERENCES}

[1] Vandersande, I.W., Ewell, R., Fleurial, J.P. and Lyon, H.B., California Institute of Technology, 1998. Cooling device featuring thermoelectric and diamond materials for temperature control of heatdissipating devices.U.S. Patent 5,712,448.

[2] Krockenberger, Y., 2006.Epitaxial thin film growth and properties of unconventional oxide superconductors. Cuprates and cobaltates.

[3] Bennemann, K.H. and Ketterson, J.B. eds., 2008. Superconductivity: Volume 1: Conventional and Unconventional Superconductors Volume 2: Novel Superconductors.Springer Science \& Business Media.

[4] Tranquada, J.M., Heald, S.M., Moodenbaugh, A.R., Liang, G. and Croft, M., 1989.Nature of the charge carriers in electron-doped copper oxide superconductors. Nature, 337(6209), p.720. 
[5] Sawa, A., Kawasaki, M., Takagi, H. and Tokura, Y., 2002.Electron-doped superconductor La 2- x Ce x CuO4: Preparation of thin films and modified doping range for superconductivity. Physical Review $B, 66(1)$, p.014531.

[6] Butch, N.P., Jin, K., Kirshenbaum, K., Greene, R.L. and Paglione, J., 2012.Quantum critical scaling at the edge of Fermi liquid stability in a cuprate superconductor. Proceedings of the National Academy of Sciences, 109(22), pp.8440-8444.

[7] Rowe, D.M. ed., 2005. Thermoelectrics handbook: macro to nano. CRC press

[8] Kundert, K.S., White, J.K. and Sangiovanni-Vincentelli, A.L., 2013. Steady-state methods for simulating analog and microwave circuits (Vol. 94). Springer Science \& Business Media.

[9] Cahill, D.G., 1990.Thermal conductivity measurement from 30 to $750 \mathrm{~K}$ : the $3 \omega$ method. Review of scientific instruments, 61(2), pp.802-808.

[10] Van Herwaarden, A.W. and Sarro, P.M., 1986. Thermal sensors based on the Seebeck effect. Sensors and Actuators, 10(3-4), pp.321-346.

[11] Getting, I.C. and Kennedy, G.C., 1970.Effect of Pressure on the emf of Chromel-Alumel and Platinum-Platinum 10\% Rhodium Thermocouples. Journal of Applied Physics, 41(11), pp.4552-4562.

[12] Pollock, D., 2017. Thermocouples: theory and properties. Routledge.

[13] Michalski, L., Eckersdorf, K., Kucharski, J. and McGhee, J., 2001. Front Matter and Index (pp. i-xv).John Wiley \& Sons, Ltd.

[14] Nath, P. and Chopra, K.L., 1974.Thermal conductivity of copper films. Thin Solid Films, 20(1), pp.53-62.

[15] Avery, A. D., Mason, S. J., Bassett, D., Wesenberg, D., \& Zink, B. L. (2015).Thermal and electrical conductivity of approximately $100-\mathrm{nm}$ permalloy, $\mathrm{Ni}, \mathrm{Co}, \mathrm{Al}$, and $\mathrm{Cu}$ films and examination of the Wiedemann-Franz Law.Physical Review B, 92(21), 214410.

[16] Pope, A. L., Zawilski, B., \&Tritt, T. M. (2001).Description of removable sample

[17] Cahill, D. G., Katiyar, M., \& Abelson, J. R. (1994).Thermal conductivity of a-Si: H thin films. Physical review B, 50(9), 6077.

[18] Cahill, D. G., Fischer, H. E., Klitsner, T., Swartz, E. T., \& Pohl, R. O. (1989).Thermal conductivity of thin films: Measurements and understanding. Journal of Vacuum Science \& Technology A: Vacuum, Surfaces, and Films, 7(3), 1259-1266.

[19] Schumann, J., Kleint, C. A., Vinzelberg, H., Thomas, J., Hecker, M., Nurnus, J., Boettner, H., Lambrecht, A., Kunzel, C., and Voelklien, F., Proceedings of $2^{\text {nd }}$ International Conference on Thermoelectrics, La Grand-Motte, p. 677, 2003.

[20] Venkatasubramanian, R., Siivola, E., Colpitts, T., \&O'quinn, B. (2001). Thin-film thermo-electric devices with high room-temperature figures of merit.Nature, 413(6856), 597-602.

[21] Lee, S. M., Cahill, D. G., \&Venkatasubramanian, R. (1997).Thermal conductivity of Si-Gesuperlattices. Applied physics letters, 70(22), 2957-2959.

[22] Kasap, S. (2001), Thermoelectric effects in metals: thermocouples.Canada: Department of Electrical Engineering University of Saskatchewan.

[23] h ttp://resources.montanainstruments.com/help/understanding-the-gifford-mcmahon-cryocooler-cycle

[24] Sun, X. F., Kurita, Y., Suzuki, T., Komiya, S., \& Ando, Y. (2004).Thermal Conductivity of P r 1.3 -X La 0.7 $\mathrm{Ce}_{\mathrm{x}} \mathrm{C}$ uO . Single Crystals and Signatures of Stripes in an Electron-Doped Cuprate.Physical review letters, 92(4), 047001.

[25] Mori, K., Tanaka, A., Nishimura, K., Isikawa, Y., Sakurai, J., Matsukawa, M., \&Noto, K. (1994). Thermal conductivity and electrical resistivity of the $\mathrm{T}^{\prime}$ phase and the $\mathrm{T}$ phase in 2-1-4 oxide superconductors. Journal of superconductivity, 7(5), 813-817.

[26] Yan, J. Q., Zhou, J. S., \&Goodenough, J. B. (2003). Thermal conductivity in the stripe-ordered phase of cuprates and nickelates.Physical Review B, 68(10), 104520.

Citation: Mervette El Batouti, et.al, "Preparation and Characterization of Unconventional Lanthanum Cerium CopurateThin Films Superconductors for Development of Thermoelectric Devices". International Journal of Advanced Research in Chemical Science (IJARCS), 6(6), pp. 3-13, DOI:http://dx.doi.org/10.20431/2349-0403.0606002

Copyright: (C) 2019 Authors. This is an open-access article distributed under the terms of the Creative Commons Attribution License, which permits unrestricted use, distribution, and reproduction in any medium, provided the original author and source are credited. 